\title{
Soropositividade para brucelose em suínos em abatedouros
}

\author{
Diego C. Rosa ${ }^{2}$, Keila C.O.D. Garcia² e Jane Megid ${ }^{2 *}$
}

\begin{abstract}
Rosa D.C., Garcia K.C.O.D. \& Megid J. 2012. [Seropositivity for brucellosis in pigs in slaughter houses.] Soropositividade para brucelose em suínos em abatedouros. Pesquisa Veterinária Brasileira 32(7):623-626. Departamento de Higiene Veterinária e Saúde Pública, Faculdade de Medicina Veterinária e Zootecnia, Universidade Estadual Paulista, Distrito de Rubião Júnior s/n, Botucatu, SP 18618-970, Brazil. E-mail: jane@fmvz.unesp.br

The aim of this investigation was to evaluate the seropositivity for brucellosis in pig slaughterhouses. Sera of 910 pigs from 30 farms and slaughtered at slaughterhouses, located in the central region of the state of São Paulo, were tested with Buffered Plate Acidified Antigen (BPAA) and 2-mercaptoethanol (2-Me) as confirmatory test to determine the serological positivity in this species. The results demonstrated that $25(2.7 \%)$ of the pigs from 10 farms reacted to BPAA, corresponding to $36 \%$ of positive properties. From BPAA positive animals $16 \%$ and $52 \%$ presented titers of 25 incomplete and 25 respectively in the Tube agglutination test (TAT), $8 \%$ presented 50 and 25 incomplete, respectively, in TAT and 2 -ME, and $8 \%$ resulted 50 and 25 positive in TAT and 2-ME, respectively. These results demonstrate the high percentage of positive farms for swine brucellosis in this region and reinforce the need for official and effective program implementation for the swine brucellosis control.
\end{abstract}

INDEX TERMS: Brucellosis, swine, slaughterhouse, antibodies, serology.

RESUMO.- 0 presente trabalho teve por objetivo investigar a soropositividade para brucelose em suínos em abatedouros. Foram coletados 910 soros de suínos, procedentes de 30 propriedades, abatidos em frigoríficos da região central do estado de São Paulo, e submetidos às provas de soroaglutinaçao com antígeno tamponado acidificado (AAT) e 2-Mercaptoetanol (2-Me) objetivando determinar a ocorrência da enfermidade nesta espécie. Do total de soros avaliados foram observados $25(2,7 \%)$ animais reagentes ao AAT pertencentes a 10 propriedades, caracterizando $36 \%$ de propriedades positivas. Dos animais positivos ao AAT, $16 \%$ apresentaram titulo de 25 (incompleto) e $52 \%$ titulo de 25 na soroaglutinação lenta (SAL), 8\% apresentaram titulo de 50 incompleto na SAL e 25 incompleto no 2-ME e $8 \%$ apresentaram titulo de 50 na SAL e 25 no 2-ME. Estes resultados demonstram o elevado percentual de propriedades positivas para brucelose nesta região e ressaltam a necessidade de implementação

\footnotetext{
${ }^{1}$ Recebido em 29 de novembro de 2011.

Aceito para publicação em 14 de fevereiro de 2012

${ }^{2}$ Departamento de Higiene Veterinária e Saúde Pública, Faculdade de Medicina Veterinária e Zootecnia Universidade Estadual Paulista (Unesp), Distrito de Rubião Júnior s/n, Botucatu, SP 18618-970, Brasil. *Autor para correspondência: jane@fmvz.unesp.br
}

de programas oficiais efetivos para o controle da brucelose suína.

TERMOS DE INDEXAÇÃO: Brucelose, suínos, abatedouros, sorologia, anticorpos.

\section{INTRODUÇÃO}

Causada por microrganismos do gênero Brucella é uma antropozoonose que afeta bovinos, suínos, caprinos, ovinos, cães e a mais recente descoberta, das espécies marinhas que afetam focas, golfinhos, baleias e leões marinhos (Godfroid 2002).

São reconhecidas atualmente 10 espécies de Brucella, sendo seis as espécies clássicas (B. abortus, B. suis, B. melitensis, $B$. canis, B. ovis, B. neotomae e, recentemente, foram descobertas as quatro novas espécies, Brucella pinnipedialis e Brucella ceti, isoladas de animais marinhos (Foster et al. 2007), Brucella microti, isolada de roedores, solo e raposas (Scholz et al. 2008a,b,c) e por último Brucella inopina$t a$, isolada de prótese mamária em humanos (Scholz et al. 2010).

A enfermidade está associada à infertilidade e ao aumento da taxa de mortalidade de leitões desmamados por ninhada, podendo alcançar índices de até $80 \%$. Essa mortalidade é insignificante em animais adultos, no entanto por- 
cas e varrões perdem seu valor podendo ser descartados devido à esterilidade (Radostits et al. 2002).

Quanto a prevalência da brucelose suína no Brasil, os dados que remetem a essa estatística são escassos, sendo descrita sua prevalência de 2,19\% em um levantamento feito em 1981 (Garcia Carrillo 1987). Posteriormente em um estudo amplo, Motta et al. (2010) analisaram soros de suínos procedentes de granjas de suinos, javalis e criatórios de suínos de 13 estados brasileiros e observaram percentagem de granjas positivas que variaram de $0,2 \%$ em javalis a $100 \%$ para granjas suínas. No estado do Tocantins, Aguiar et al. (2006) observaram 0,9\% de positividade em 109 soros suínos avaliados em Monte Negro. No estado de São Paulo, Feitosa et al. (1991) realizaram um levantamento de 10 anos, correspondente ao período de 1977 a 1987 e observaram uma prevalência de 13,23\% em suínos. Dados bastante preocupantes são observados na leitura do trabalho desenvolvido por Freitas et al. (2001) que, analisando soros procedentes de suínos de abate clandestino, caracterizaram $42,2 \%$ de positividade ao AAT. Apesar destes relatos, a brucelose no Brasil é uma doença subdiagnosticada e subnotificada (Brasil 2006).

Os dois biovares mais comuns de Brucella suis são também patógenos humanos sendo necessário, portanto, a implantação de algumas medidas preventivas como manipulação laboratorial de culturas ou material contaminado em condições estritas de biossegurança (OIE 2009).

$B$. suis é considerada a segunda espécie mais patogênica aos seres humanos e a enfermidade em suínos tem por característica a disseminação deste agente pela corrente sanguínea com bacteremias recorrentes e presença da bactéria em órgãos e linfonodos (Deyoe 1986). Adicionalmente, em função da bacteremia o consumo da carne de suínos, de forma mal passada ou crua, representa um risco elevado aos seres humanos para a aquisição da enfermidade se caracterizando como importante fator na saúde pública a ser considerado (Garcia-Carrilho 1987).

Em sua forma ocupacional, a doença, no homem, ocorre pela exposição a B. abortus e B. suis em abatedouros, frigoríficos, manipulação de carne ou de produtos derivados, ordenha e fabricação de laticínios e atividades assemelhadas (Brasil 2001).

As taxas de incidência de brucelose humana foram menores em países que adotaram programas de combate à brucelose animal demonstrando ser esse o caminho para evitar a infecção, que, mesmo não sendo tão disseminada na população humana, pode dar origem a um quadro clínico grave, com sérias complicações para as pessoas acometidas (Mathias 2008).

Em investigação epidemiológica na Flórida (Bigler et al. 1977) descobriu-se que $22 \%$ (6 de 27) dos casos humanos, durante o período de 1974-1975, foram atribuídos ao contato de caçadores com porcos selvagens.

0 abate clandestino de suínos, embora seja uma prática inaceitável, ocorre em todo o país, por tal se configura num importante foco de infecções e risco à saúde pública pela exposição coletiva a agentes infecciosos, como aqueles que são transmitidos ao homem pelo contato com animais, pela ingestão de alimentos de qualidade sanitária suspeita e pela contaminação do meio ambiente. Contudo, apesar dos fatos, o risco associado a esses abatedouros não parece ter a devida atenção (Hunter et al. 1994). Em função da ausência de diagnóstico rotineiro, não se conhece a situação sanitária dos suínos encaminhados para abate em frigoríficos com inspeção, informação que fornece dados sobre a situação epidemiológica da brucelose.

Considerando as escassas informações e o risco de transmissão da brucelose suína ao ser humano, o objetivo deste trabalho foi avaliar o percentual de positividade para brucelose em suínos pertencentes a diferentes propriedades e abatidos em frigoríficos da região central do estado de São Paulo.

\section{MATERIAL E MÉTODOS}

Foram colhidos e analisados sorologicamente sangue de suínos provenientes dos Municípios de São Carlos, Bariri, São Manuel, Tietê, Areiópolis, Botucatu, Bauru, Itaberá, Itapetininga, Fartura, Paranapanema, Birigui, Afonso e Holambra no total de 910 soros, sendo 448 fêmeas e 462 machos procedentes de 30 diferentes propriedades. Durante a colheita foram obtidas as informações relativas a origem e sexo dos animais e observadas possíveis lesões macroscópicas.

Os soros obtidos foram congelados e submetidos posteriormente às provas sorológicas para diagnosticode brucelose, sendo utilizado como triagem o Teste do Antígeno Acidificado Tamponado (AAT) seguida da Prova do 2-Mercaptoetanol (2-ME) que foi constituída pela realização em paralelo das provas de Soroaglutinação lenta (SAL) e 2-ME, considerada confirmatória dos resultados positivos no AAT, de acordo com a metodologia do Programa Nacional de Controle e Erradicação da Brucelose e Tuberculose Bovina (PNCEBT) (BRASIL 2001). Os resultados foram avaliados com base na positividade ao AAT (OIE 2009) porém levou-se em consideração para discussão os resultados observados no 2-ME, considerando de forma individualizada os títulos observados na SAL e 2-ME.

\section{RESULTADOS}

Nenhum dos animais avaliados apresentava qualquer tipo de lesão macroscópica sendo considerados, aparentemente, sadios. Do total de soros analisados, 25 (3\%) foram positivos ao AAT, sendo 10 (40\%) pertencentes a fêmeas e 15 $(60 \%)$ a machos.

Quanto a procedência dos animais positivos ao AAT, sete (28\%) pertenciam ao município de São Manuel, um (4\%) de Botucatu, seis (24\%) de Areiópolis, quatro (16\%) de São Carlos, três (12\%) de Bariri totalizando 10 (36\%) propriedades positivas e $100 \%$ delas pertencentes a região central do estado de São Paulo conforme demonstra a Figura 1. Os resultados, ao AAT, caracterizaram $3 \%$ de soropositividade de forma global e $36 \%$ de propriedades com animais positivos no presente trabalho

Dos animais positivos ao AAT, quatro (16\%) foram negativos nas provas de SAL e 2-ME, quatro $(16 \%)$ apresentaram titulo de 25 (incompleto) e 13 (52\%) apresentaram titulo de 25 na SAL, dois (8\%), apresentaram titulo de 50 incompleto na SAL e 25 incompleto no 2-ME e dois (8\%) apresentaram titulo de 50 na SAL e 25 no 2-ME. Os resultados estão expressos no Quadro 1. 


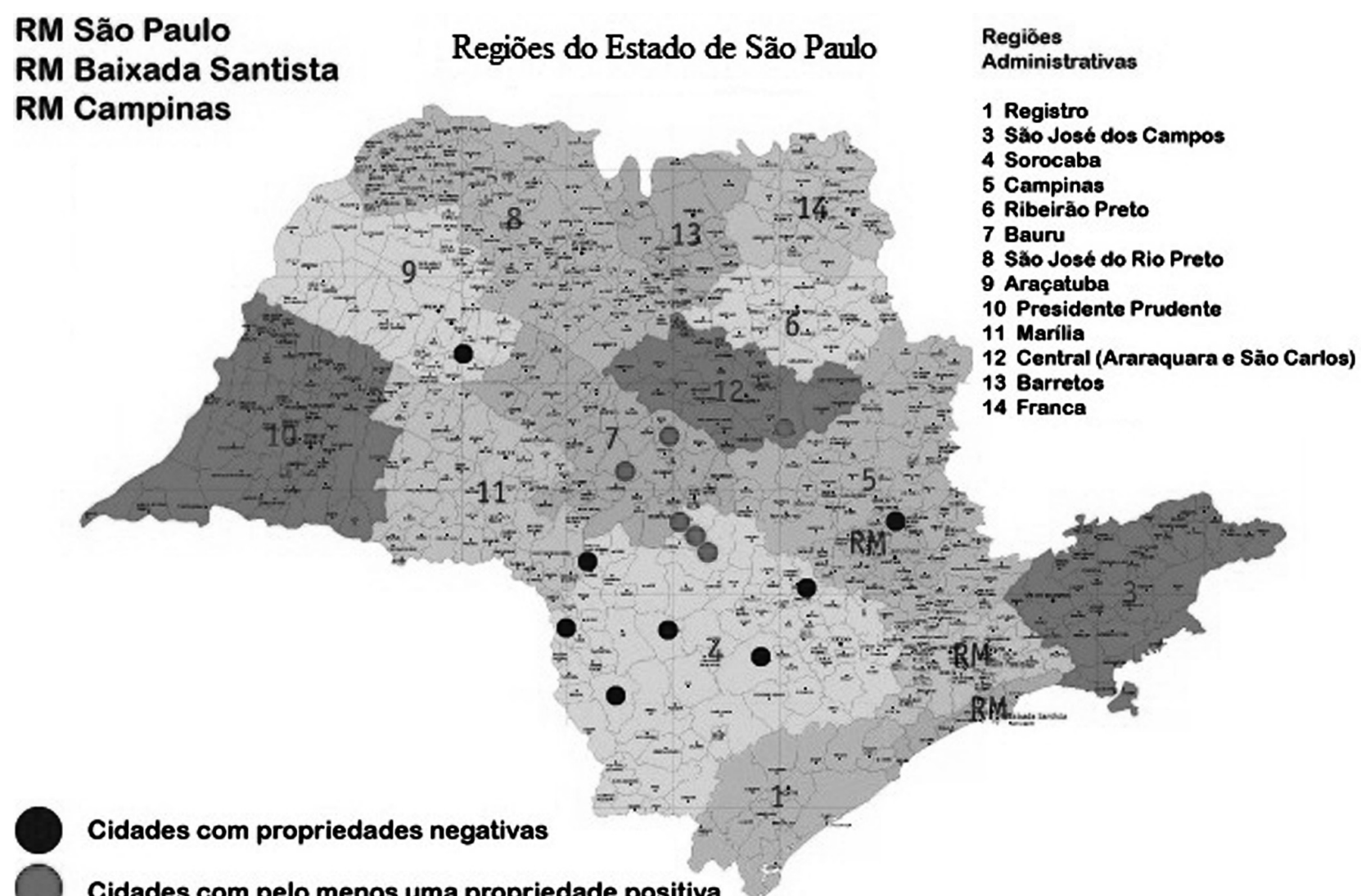

Fig. 1. Procedência e positividade ao AAT dos soros de suínos obtidos no Estado de São Paulo. (Fonte. COPESP- Mapa das Regiões Metropolitanas do Estado de São Paulo)

Quadro 1. Número de animais, porcentagem de positivos total e títulos obtidos, de acordo com o sexo, nas diferentes provas sorológicas complementares nos soros de suínos positivos ao Antígeno Tamponado Acidificado em suínos abatidos em frigoríficos do Estado de São Paulo

\begin{tabular}{|c|c|c|c|c|c|c|c|c|c|}
\hline & \multicolumn{6}{|c|}{ Titulos na soroaglutinação lenta } & \multicolumn{2}{|c|}{ Sexo dos animais } & \multirow[t]{2}{*}{ Total } \\
\hline & & Neg. & $25 \mathrm{i}$ & 25 & $50 \mathrm{i}$ & 50 & Fêmea & Macho & \\
\hline \multirow[t]{5}{*}{ Titulos no 2-Mercaptoetanol } & Neg. & 4 & & & & & 1 & 3 & $4(16 \%)$ \\
\hline & Neg. & & 4 & 13 & & & 8 & 9 & $17(68 \%)$ \\
\hline & $25 \mathrm{i}$ & & & & 2 & & 1 & 1 & $2(8 \%)$ \\
\hline & 25 & & & & & 2 & 0 & 2 & $2(8 \%)$ \\
\hline & Total & & & & & & $10(40 \%)$ & $15(60 \%)$ & $25(100 \%)$ \\
\hline
\end{tabular}

$\overline{\mathrm{i}=\text { Reação incompleta. }}$

\section{DISCUSSÃO}

Neste experimento, não foram observados animais positivos para a brucelose suína se tomarmos por base a interpretação preconizada pela Portaria no. 23, de 20 de janeiro de 1976 (Ministério da Agricultura e do Abastecimento) que considera positivo qualquer animal com título 25 na SAL desde que pertencente a rebanhos com suínos positivos (pelo menos um animal com título 100 na SAL) e sendo considerado o título 100 na SAL como positivo para suínos independente dos títulos nos outros animais pertencentes ao rebanho analisado.

No entanto, a OIE (2009) preconiza que, dentre outros testes, a prova do antígeno tamponado acidificado (AAT) é um dos melhores testes para diagnóstico de infecção por Brucella sp. em suínos, sendo o teste recomendado para exportação desses animais. Com base nisso observamos um percentual de $3 \%$ de soropositividade de forma global e $36 \%$ de propriedades com animais positivos no presente trabalho. Os resultados obtidos demonstram, portanto, de acordo com a OIE (2009), uma ampla disseminação da brucelose em suínos evidenciada pelo número de propriedades positivas nesta região estudada.

0 envio destes animais para abate representa um risco aos magarefes que manipulam sem cuidados especiais e aos consumidores de forma geral, uma vez que não apresentam lesões indicativas da doença, como observado em nosso experimento. 0 percentual de positividade observado neste trabalho assim como os relatados por outros autores sugere que a brucelose suína se encontra presente em nosso país de forma importante, representada não exatamente pela prevalência da enfermidade, mas sim pelo percentual de propriedades positivas, que são definidas por apresentarem pelo menos um animal reagente a brucelose (Motta et al ,2010). Uma vez que a sorologia aplica- 
da detecta positividade para amostras lisas de Brucella (B. abortus, B. suis e embora não diagnosticada em nosso país, também para B. melitensis) (MacMillan 1990) não se pode afirmar se estes animais se encontram infectados por $B$. suis ou B. abortus, porém, dentre as encontradas em nosso país, são as espécies de maior patogenicidade ao ser humano. Por outro lado, é bastante comum, especialmente em propriedades pequenas, a criação mista de várias espécies, das quais rotineiramente estão presentes os bovinos e suínos, representando, adicionalmente, um risco ao sucesso do PNCEBT uma vez que estes animais se constituem em fonte de infecção para os bovinos e vice versa. Ressalta-se, desta forma, a necessidade de estudos epidemiológicos amplos direcionados a avaliar a prevalência da brucelose suína em nosso país, com vistas a futura implementação de programas de controle para a enfermidade em suínos de forma similar a aplicada aos bovinos e também de projetos de conscientização da população sobre os riscos da ingestão de alimentos sem processamento térmico adequado.

O Estado de São Paulo se integrou ao Programa Nacional de Controle e Erradicação de Brucelose e Tuberculose Bovina, através da Coordenadoria de Defesa Agropecuária (CDA), institucionalizado pelo Ministério da Agricultura, Pecuária e Abastecimento (MAPA). 0 programa visa promover a qualidade dos produtos de origem animal oferecido ao consumidor e modernizar as cadeias produtivas do leite e da carne pela melhora na eficácia das medidas de combate à brucelose e à tuberculose. Dada a importância do programa, o CDA está implantando uma série de projetos correlatos, dentre eles o Projeto Abatedouros como instrumento de rastreabilidade de focos de tuberculose bovina no Estado de São Paulo (CDA 2004). A utilização de frigoríficos para vigilância epidemiológica de enfermidades envolvidas em programas de controle nacional ou mesmo de caráter zoonótico abre uma nova possibilidade no sistema de vigilância. A vigilância epidemiológica da brucelose, em frigoríficos, nos moldes aplicados à tuberculose, porém direcionada a colheita de sangue de determinado numero de animais pertencentes a diferentes propriedades, possibilitará o monitoramento dos rebanhos de corte procedentes de propriedades que aderiram ao PNCEBT com a finalidade de obtenção de certificado de propriedade monitorada. Adicionalmente, dentro do programa de rastreabilidade, fornecerá ao mercado interno e externo a segurança quanto ao padrão sanitário específico para brucelose permitindo a agregação do valor à qualidade da carne obtida. Em situações de rebanho não monitorado possibilitará o conhecimento dos focos permitindo ações de controle direcionadas ao rebanho e à saúde pública. Dentro deste enfoque estes objetivos também poderiam ser utilizados aos abatedouros suínos garantindo qualidade de carne ao consumidor e menores riscos a saúde pública além da vigilância epidemiológica do rebanho nacional.

Desse modo, pode-se diminuir de maneira acentuada os danos causados a saúde animal, saúde pública, além de restringir os prejuízos causados à economia do país.

Agradecimentos.- À FAPESP pela concessão de bolsa de Iniciação cientifica a Diego Catto da Rosa. À Fundunep pelo auxílio financeiro para este projeto.

\section{REFERÊNCIAS}

Aguiar D.M., Cavalcante G.T., Dib C.C., Villalobos E.M.C., Cunha E.M.S., Lara M.C.C.S.H., Rodriguez C.A.R., Vasconcellos S.A., Moraes Z.M., Labruna M.B., Camargo L.M.A. \& Gennari S.M. 2006. Anticorpos contra agentes bacterianos e virais em suínos de agricultura familiar do município de Monte Negro, RO. Arqs Inst. Biológico, São Paulo, 73:415-419.

Brasil 1976. Portaria no 23 de 20 de Janeiro de 1976, Ministério da Agricultura, Pecuária e Abastecimento, Brasília. <http://extranet.agricultura.gov.br/sislegis/action/detalhaAto.do?method=consultarLegislacao $\mathrm{F}$ ederal> Acesso em 15 out. 2010.

Brasil 2001. Doenças relacionadas ao trabalhado. Série A, Normas e Manuais Técnicos no. 114, Ministério da Saúde, Brasília. 580p.

Brasil 2006. Doenças infecciosas e parasitárias: guia de bolso. Série B, Textos Básicos de Saúde. 5a ed. Departamento de Vigilância Epidemiológica, Secretaria de Vigilância em Saúde Pública, Ministério da Saúde, Brasília, p.65-68.

Bigler W.J., Hoff G.L., Hemmert W.H., Tomas J.A. \& Janowski H.T. 1977. Trends of brucellosis in Florida. Am. J. Epidemiol. 105:245-251.

CDA 2004. Abatedouros como instrumento de rastreabilidade de focos de tuberculose bovina no Estado de São Paulo. Coordenadoria de Defesa Agropecuária do Estado de São Paulo. <http://www.cda.sp.gov.br/ www/legislacoes/index.php\#> Acesso em 20 out. 2010.

COPESP 2008. Mapa das regiões administrativas do Estado de São Paulo. <http://www.copesp.org/regionais.html> Acesso em 16 nov. 2008.

Deyoe B.L. 1986. Brucellosis, p.599-607. In: Leman A.D., Straw B., Glock R.D., Mengeling W.L., Penny R.H.C. \& Scholl E. (Eds), Diseases of Swine. $6^{\text {th }}$ ed. Iowa State University Press, Ames.

Garcia-Carrillo C. 1987. La brucelosis de los animales en America y su relacion con la infeccion humana. Office International des Epizooties, Paris, p.43-70.

Godfroid J. 2002. Brucellosis in wild life. Rev. Sci. Tech. Off. Int. Epizoot. 21:277-286.

Feitosa M.H., Bittar C.R. \& Gomes S.P. 1991. Brucelose: levantamento sorológico no Estado de São Paulo no período de 1977 a 1987. Vet. Zootec. 3:9-15.

Foster G., Osterman B.S., Godfroid J., Jacques I. \& Cloeckaert A. 2007. Brucella ceti sp. nov. and Brucella pinnipedialis sp. nov. for Brucella strains with cetaceans and seals as their preferred hosts. Int. J. Syst. Evol. Microbiol. 57:2688-2693.

Freitas J.A., Galindo G.A.R., Santos E.J.C., Sarraf K.A. \& Oliveira J.P. 2001. Risco de brucelose zoonótica associado a suínos de abate. Revta Saúde Pública 35:101-102.

Hunter L., Smith C.G. \& MacCormack J.N. 1994. Brucellosis outbreak at a pork processing plant, North Carolina. Morb. Mort. Wkly Rep. 43:113-116.

MacMillan A. 1990. Conventional serological test, p.153-198. In: Nielsen K. \& Duncan R. (Eds), Animal Brucellosis. CRC Press, Boca Raton, FL.

Mathias L.A. 2008. Brucelose suína e suas implicações em saúde pública. Biológico, São Paulo, 70:47-48.

Motta P.M.C., Fonseca Jr A.A., Oliveira A.M., Nascimento K.F., Soares Filho P.M., Serra C.V., Jesus A.L., Rivetti Jr A.V., Ramalho A.K., Mota P.M.P.C., Assis R.A. \& Camargos M.F. 2010. Inquérito soroepidemiológico para brucelose em suídeos do Brasil. Vet. em Foco 7:141-147.

OIE 2009. Porcine Brucellosis. NB: Version adopted by the World Assembly of Delegates of the Office International des Epizooties, Paris.

Radostits O.M., Gay C.C. \& Hinchcliff K.W. 2002. Clínica Veterinária. 9ā ed. Guanabara Koogan, Rio de Janeiro, p.794-798.

Scholz H.C., Hubalek Z., Sedlácek I., Vergnaud G., Tomaso H. \& Al Dahouk S. 2008a. Brucella microti sp. nov., isolated from the common vole Microtus arvalis. Int. J. Syst. Evol. Microbiol. 58:375-382.

Scholz H.C., Hubalek Z., Nesvadbova J., Tomaso H., Vergnaud G. \& Le Fleche P. 2008b. Isolation of Brucella microti from soil. Emerg. Infect Dis. 14:1316-1317.

Scholz H.C., Hofer E., Vergnaud G., Le Fleche P., Whatmore A.M. \& Al Dahouk S. 2009. Isolation of Brucella microti from mandibular lymph nodes of red foxes, Vulpes vulpes, in lower Austria. Vector Borne Zoonotic. Dis. 9:153-156.

Scholz H.C., Nockler K., Gollner C., Bahn P., Vergnaud G. \& Tomaso H. 2010. Brucella inopinata sp. nov., isolated from a breast implant infection. Int. J. Syst. Evol. Microbiol. 60:801-808. 